\title{
First-born Child’s Attitude Towards Potential Siblings Under the "Selective Two-Child Policy” in China*
}

\author{
Wu JianFen \\ Hangzhou Normal University, \\ Hangzhou, China
}

\author{
Wu YunPeng \\ Shandong Normal University, \\ Ji'nan, China
}

\author{
Su HuiXin, Wang QiuLi \\ Hangzhou Normal University, \\ Hangzhou, China
}

\begin{abstract}
With the implementation of the "selective two-child policy" which was released by the Chinese government, some couples with one child are planning to have the second child. The present study intends to investigate the first-born child's attitude towards potential siblings as well as the factors that influence his/her attitude. With interviews and painting analysis of children from middle classes and senior classes of kindergarten, this study explore their attitudes to potential siblings and its influencing factors from the perspective of child. The interpretations of the influencing factors of their attitudes are beneficial for offering strategies for their role transformation. Intervention strategies for the well-being of first-born child were discussed.
\end{abstract}

Keywords: selective two-child policy, first-born child, attitude, sibling

\section{Research Background}

China implemented OCP (the One-Child Policy) in 1979 and resulted in millions of only-children in China. China possesses the world's largest number of only-children in the world. So as to gradually adjust and improve family planning policy, promote the balanced development of long-term population, the Chinese government began softening the OCP in 2001 by implementing "selective two-child policy" which allows couples to have a second child if both of the parents were only children (Xin Hua News Agency, 2001). In 2013, the OCP was further modified to allow couples to have a second child if one of the parents is an only child (The 18th Session of the Central Committee of the Communist Party of China, The Third Plenary Session, 2013). A survey of National Health and Family Planning Commission of China indicated that this policy will affect 15 million to 20 million people. The survey on these only-child parents suggested that $47 \%$ of them are willing to have the second child, yet 30\% are still hesitant. Many families will have the second child and their first-born child will have younger siblings (a younger brother or sister).

Some studies have investigated the influences of the "selective two-child policy", and suggested the psychological influences of first-born child may face (Zhou \& Qiao, 2014). However, there is rarely study on the attitude of first-born child towards their potential younger siblings from the perspective of first-born child.

\footnotetext{
* This research was funded by Social sciences planning project of Zhejiang Province (Mixed-age education Research based on “Theory of Mind” of Children, Grant NO.11JCJY10YB ) and the Program for Excellent Young Teachers in Hangzhou Normal University (HNUEYT2011-01-002).

Wu JianFen, Ph.D., School of Education , Hangzhou Normal University.

Wu YunPeng, Ph.D., School of Psychology, Shandong Normal University.

Su HuiXin, M.Ed. School of Education, Hangzhou Normal University.

Wang QiuLi, M.Ed. School of Education , Hangzhou Normal University.
} 
Meanwhile, little attention has been paid to the changes of first-born child since the born of the second child in the families with two children. In this regard, the current study applied interview and painting analysis to investigate first-born child's attitude. Taking the content of interview with parents in to consideration, we proposed suggestions for parents with the second child as well as the parents who plan to have the second child.

\section{Method}

\section{Interview}

The current study selected 60 children (30 boys and 30 girls) as subjects for interview, among which 30 from middle classes (age range: 4-5) and 30 from senior classes (age range: 5-6) of kindergarten in Hangzhou, Zhejiang Province, China. We designed simple and direct questions that can be understood by children. We interviewed child in two kinds of settings: (1) daily activities; and (2) talk activities in the kindergarten, so as to carry out the interview naturally. We also interviewed 30 parents to investigate their experiences with their children.

\section{Painting Analysis}

Children have the desire to express their feelings; however, they lack rich language abilities to express themselves. Painting, as a special language, offers children a way to express their internal world and life experiences. The painting of children, to some degree, can reflect their thoughts in their minds. Thus the current study applied painting analysis method to investigate children's attitudes towards younger siblings. The teacher asked the children to draw a painting with the topic of "If I had a younger sister". After children finished the painting, they were invited to illustrate their painting to the researcher.

\section{Results}

Most of the first-born children welcome their younger siblings.

\section{Results of Interview}

The interview with children indicated that most children (50 out of 60) welcome their younger siblings. Chi-squared tests indicated that there was no significant difference between the children with different genders $(p=0.225)$ or child in different age groups $(p=0.474)$.

Table 1

Child's Attitudes Toward Younger Siblings

\begin{tabular}{|c|c|c|c|c|c|}
\hline & \multicolumn{2}{|c|}{ Child gender } & \multicolumn{2}{|c|}{ Age group } & \multirow[t]{2}{*}{ Tota } \\
\hline & Boy & Girl & Middle Class & Senic & \\
\hline Accept & 26 & 24 & 24 & 26 & 50 \\
\hline Reject & 4 & 6 & 6 & 4 & 10 \\
\hline
\end{tabular}

Their imaginations of the life with younger siblings would be "sweet" and "happy". During the interview, the children rarely mentioned the conflict they may face, nor did they realize that they must share family resources with younger siblings. Even when the researcher proposed the conflict they may face, the children still willing to accept that situation. They expressed their admiration for the children with siblings who can play together and be companies to each other. They express their like to younger siblings who would play with them. We should also notice that the quality of "be obedient" is an important characteristic these first-born children expect their younger siblings to have. 
Meanwhile, several children (10 out of 60) expressed their rejection to the born of younger siblings. They consider them as a burden for themselves. They think that younger siblings may "grab" parents' love to them and cause them be out of favor.

\section{Results of Painting Analysis}

The analysis of the paintings indicated same results. We collected 40 topic-assigned paintings. Three paintings were of no relevance to the topic, thus were excluded from the analysis.
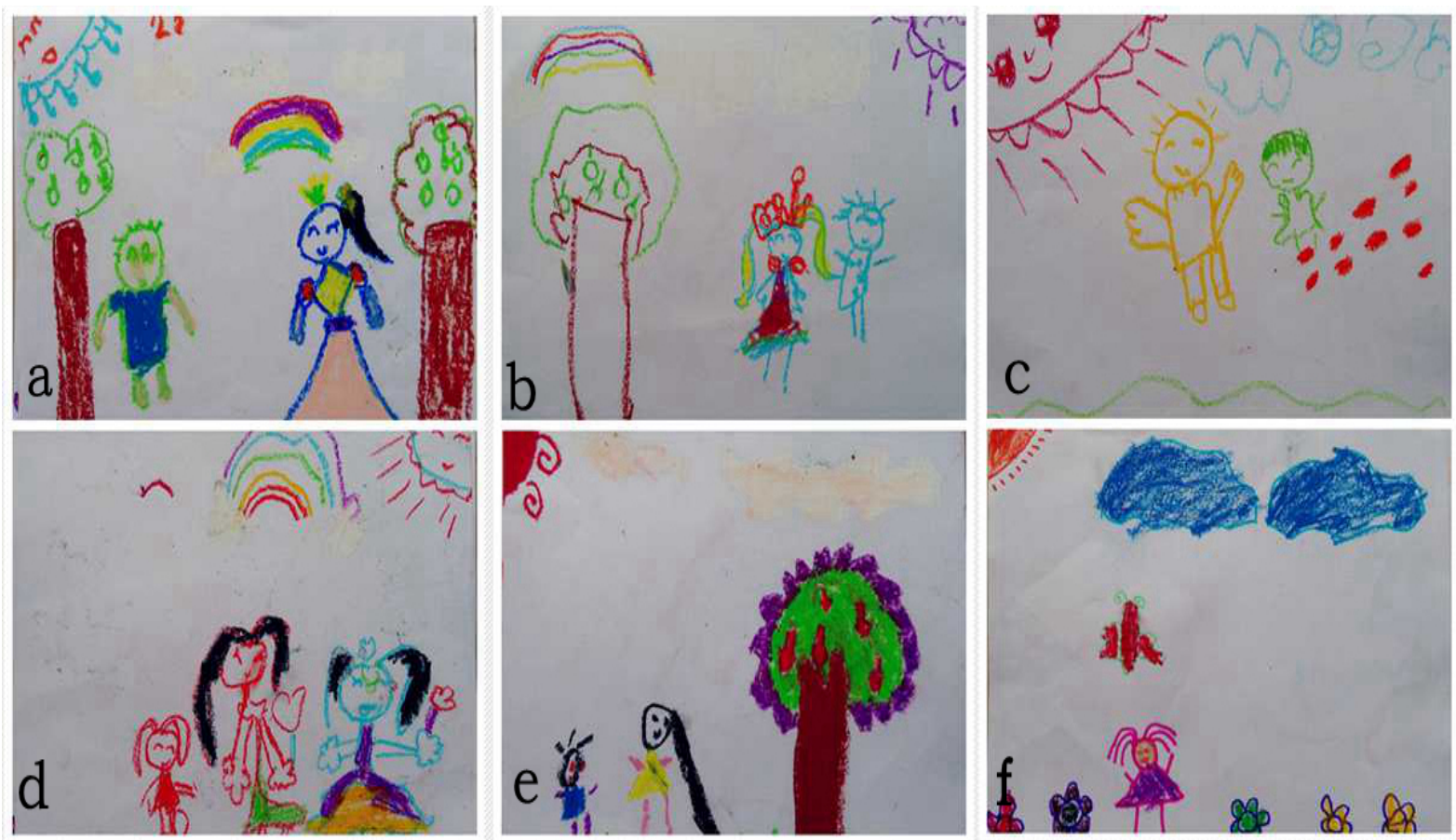

Figure 1. Examples of the paintings of children.

Totally the colors of 35 out of 37 painting was mainly warm color (Figure 1) which reflects the psychological emotion of positive, enjoy, and warmth. Among these paintings, 35 paintings reflect children's love to their younger siblings. The paintings depicted that they are playing with each other. In their narrations of their paintings, they mainly mentioned "play together", "happy", and "like".

However, in the narrations of two children of their paintings, the children rejected to have a younger sibling. For example, in the painting $\mathrm{f}$ of Figure 1, there is only one child which was illustrated as the child himself. They expressed their objection to the idea of having a younger sibling. The reasons for their rejections are "Dad and Mom would love me less if I have a younger brother or sister" and "The younger brother or sister usually cries, and it is annoying. That would bother me". Child is very possessive and sensitive. The worry of the deprival of parents' love is a common concern.

\section{The Factors That Influence Child's Attitude}

\section{Being a Companion}

The factor of "being a companion" is a key factor that count for child's love for their younger sibling. Interview with parents suggested that, in China, the only-child usually feel lonely, especially when they stay at home without company. Having two children in the family can eliminate the lonely feeling of child. However, 
it should be noted that some children also expressed their dislike for younger siblings who are "too young that need I to take care of them" and who "bother me a lot". First-born children usually like the younger sibling "who are behave themselves".

\section{Parenting Style of Parents}

Table 2

The Percentage of First-Born Child's Attitude to Younger Sibling With Different Parenting Styles (\%)

\begin{tabular}{llcll}
\hline & Authoritarian & Neglect & Indulgent & Authoritative \\
\hline Accept & 11.67 & 5 & 33.3 & 50 \\
Reject & 88.33 & 95 & 66.7 & 50 \\
\hline
\end{tabular}

Interview with parents indicated that children under neglect, authoritarian, and indulgent parenting style usually dislike their younger siblings. The only-child in China usually possess the center of the family which make them get used to the self-centered thought. They generally lack the ability to share. In their view, younger sibling may "rob" them of parents' love. This thought will cause pressure for them and lead them to reject the born of the second child. In contrast, the authoritative parenting foster the development of child's positive and self-confident characteristics. Children with such parenting style generally show care, understanding, trust, and respect to others. Thus when parents propose the idea of "borning a younger sibling for you", they are more will to accept and show supportive attitude.

\section{Reflection and Innovation}

Generally speaking, the firs-born children welcome the "coming" of the second child. They desire the company of the second child. Yet they reject the trouble that second child may cause to them. A few of the child dislike the born of younger sibling for the fear that younger sibling may rob parents' attention and love from them.

Meanwhile, the behaviors of parents still need some improvement. In current study, parents that already had the second child stated that they intend to treat the two children equally. However, 2/3 of the non-only-children in current study declared that their parents failed to treat them and their siblings equally. Thus we propose some suggestions for the health development of first-born children.

\section{Parents Should Pay Close Attention to First-Born Child's Emotion}

Unlike the good wishes of the parents who plan to have the second child, the first-born child's attitude seems not as positive as expected. During the interview, some parents said that child showed differences in attitudes before and after mother's pregnancy. When asked about the reason, the first-born children worry that when they have a younger brother or sister, parents may not love them as much as before. Some children also worry that their favorite toys or food will be carved up by their younger brother or sister.

For the only child who has always been the center of a family, they have been used to the situation that parents only love themselves. They firmly hold the misleading belief that "I'm unique; mom and dad can only be nice to me". When they have a brother or sister, they will feel that their love has been taken away and experience the sense of loss. Therefore, for couples that qualified the selective second child policy, before having the second child, they should communicate with the first-born child patiently, and don't neglect their feelings. Parents should convince them that even if parents have another baby, they will not lose the care and love of parents, thus reduce their sense of crisis. 


\section{Parents Need to Apply Improved Parenting Practices}

Parenting practices also play significant role on the development of sibling relationship (Milevsky, Schlechter, \& Machlev, 2011). Firstly, parents should not always ask the first-born child to be forbearing and conciliatory during sibling conflict with the reasons like "Your brother is younger than you" or "As you are the older brother/sister". The conflict between two kids should be solved fairly. Reasonable analysis of the conflict and training of perspective taking is an effective way for conflict solving. Secondly, parents should avoid making improper comparison be two children. Some parents usually express the idea that "Your younger sister/brother is cuter than you" or "You are not as obedient as your younger sibling". Research indicate that, as child grow up, they become more sensitive to their relationship with important others (e.g. parents), thus order child are more likely to feel jealousy and upset than younger child (Masciuch \& Kienapple, 1993).

\section{Mixed-age Education Should Be Promoted}

The mixed-age education were originally set up and organized in accordance with the work of Vygotsky who suggested that children can learn through imitation, or "emulation”. It has been developed rapidly (Smit, Hyry-Beihammer, \& Raggl, in press). For the only children in China, mixed-age education offers them the opportunity to play with children with different ages (Cheng, 2010). Researcher also proposed suitable forms of mixed-age education in China (Wu \& Chen, 2006). Firstly, mixed-age education is beneficial for the fostering of child's sense of responsibility and love for younger children. This may increase the first-born child's expectation of having a younger siblings. Secondly, mixed-age education can also improve child's social skills to get along with children with different age. This can promote the first-born child to get along well with siblings.

\section{References}

Cheng, C. L. (2010). On the mixed-age kindergarten education for 3-6 years old children. Studies In Preschool Education, 11, 61-63.

Masciuch, S., \& Kienapple, K. (1993). The emergence of jealousy in children 4 months to 7 years of age. Journal of Social \& Personal Relationships, 10(3), 421-435.

Milevsky, A., Schlechter, M. J., \& Machlev, M. (2011). Effects of parenting style and involvement in sibling conflict on adolescent sibling relationships. Journal of Social \& Personal Relationships, 28(8), 1130-1148.

Smit, R., Hyry-Beihammer, E. K., \& Raggl, A. (in press). Teaching and learning in small, rural schools in four European countries: Introduction and synthesis of mixed-/multi-age approaches. International Journal of Educational Research.

The 18th session of the central committee of the communist party of China, the third plenary session. (2013). The central committee of the communist party of China on several major issues comprehensively deepen reform. Retrieved from http://www. sn.xinhuanet.com/2013-11/16/c_118166672.htm

Wu, J. F., \& Chen, B. M. (2006). Discontinuous mixed-age education: A preschool education form suitable in China. Early Childhood Education, 3, 6-7. (in Chinese)

Xin Hua News Agency. (2001, July 21). The bill of population and birth planning emphasizes the stability of current policy. Retrieved from http://www.china.com.cn/chinese/renkou/91445.htm (in Chinese)

Zhou, N. L., \& Qiao H. H. (2014). The psychological challenges the first-born child may facing with the implementation of “selective two-child policy”. Chinese Journal of Family Planning, 22(8), 570-573. 